\section{Oncogenic RAS directs silencing of tumor suppressor genes through ordered recruitment of transcriptional repressors}

\author{
Narendra Wajapeyee, ${ }^{1,5,6}$ Sunil K. Malonia, ${ }^{2,3,4,5}$
}

Rajendra K. Palakurthy, 2,3,4

and Michael R. Green ${ }^{2,3,4,6}$

${ }^{1}$ Department of Pathology, Yale University School of Medicine, New Haven, Connecticut 06520, USA; ${ }^{2}$ Howard Hughes

Medical Institute, ${ }^{3}$ Program in Gene Function and Expression,

${ }^{4}$ Program in Molecular Medicine, University of Massachusetts

Medical School, Worcester, Massachusetts 01605, USA

We previously identified 28 cofactors through which a RAS oncoprotein directs transcriptional silencing of Fas and other tumor suppressor genes (TSGs). Here we performed RNAi-based epistasis experiments and found that RAS-directed silencing occurs through a highly ordered pathway that is initiated by binding of ZFP354B, a sequencespecific DNA-binding protein, and culminates in recruitment of the DNA methyltransferase DNMT1. RNAi and pharmacological inhibition experiments reveal that silencing requires continuous function of RAS and its cofactors and can be rapidly reversed, which may have therapeutic implications for reactivation of silenced TSGs in RAS-positive cancers.

Supplemental material is available for this article.

Received July 25, 2013; revised version accepted September 10, 2013.

The conversion of a normal cell to a cancer cell is a stepwise process that typically involves the activation of oncogenes and inactivation of tumor suppressor genes (TSGs) (Hanahan and Weinberg 2011). There are two general mechanisms by which TSGs are inactivated. First, the TSG can acquire a deletion or mutation that abrogates the function of the encoded protein (Berger et al. 2011; Vogelstein et al. 2013). Second, the TSG can become transcriptionally silenced by a process commonly referred to as "epigenetic silencing" (Kulis and Esteller 2010). Transcriptionally silenced TSGs have characteristic features of heterochromatin, including inhibitory histone modifications and hypermethylated DNA regions.

Formally, epigenetic gene regulation refers to a change in gene expression that occurs in the absence of any

[Keywords: DNMT1; epigenetic silencing; epistasis analysis; RAS; RNA interference; ZFP354B]

${ }^{5}$ These authors contributed equally to this work.

${ }^{6}$ Corresponding authors

E-mail michael.green@umassmed.edu

E-mail narendra.wajapeyee@yale.edu

Article published online ahead of print. Article and publication date are online at http://www.genesdev.org/cgi/doi/10.1101/gad.227413.113. change in DNA sequence and can be inherited in the absence of the signal (or event) that initiated the change (Ptashne 2007). Whether transcriptional inactivation of TSGs is truly epigenetic (i.e., whether it can be inherited in the absence of the initiating signal) remains to be determined.

As a model system for studying transcriptional inactivation of TSGs, we studied silencing of Fas in oncogenic RAS-transformed cells (Gazin et al. 2007). Expression of a RAS oncoprotein in mouse NIH 3T3 cells transcriptionally silences Fas, thereby preventing Fas ligandinduced apoptosis (Peli et al. 1999). Previously, we performed a genome-wide RNAi screen to identify 28 cofactors required for RAS-mediated silencing of Fas (Gazin et al. 2007). We further showed that a number of these factors are directly associated with specific regions of Fas in Kras-transformed NIH 3T3 cells but not in untransformed NIH 3T3 cells.

Here we used RNAi to perform experiments analogous to classical epistasis analyses to order the 28 cofactors into a pathway. Based on this information, we went on to study the initiation, maintenance, reversibility, and kinetics of RAS-directed silencing of TSGs.

\section{Results and Discussion}

We previously derived and characterized a series of 28 Kras NIH 3T3 knockdown cell lines, each of which is depleted for one of the 28 cofactors required for Fas silencing, resulting in Fas reactivation (Gazin et al. 2007). We further demonstrated that the shRNAs used to derive these cell lines efficiently and specifically knock down their target gene (Supplemental Fig. S1; Gazin et al. 2007). To order the 28 components into a pathway, we monitored binding of 12 cofactors that are stably associated with transcriptionally silenced Fas in the 28 Kras NIH $3 \mathrm{~T} 3$ knockdown cell lines. We reasoned that if a Kras NIH 3T3 knockdown cell line supports binding of a particular cofactor, then the gene knocked down in that cell line is dispensable for binding and can be placed downstream in the pathway. In contrast, if a Kras NIH 3 T3 knockdown cell line fails to support binding of a particular cofactor, then the gene knocked down in the cell line is required for binding and can be placed upstream in the pathway.

We monitored cofactor binding to Fas using three sets of promoter-specific primer pairs that cover the entire Fas promoter region: $\sim 2 \mathrm{~kb}$ upstream of the transcription start site (TSS), $\sim 1 \mathrm{~kb}$ upstream of the TSS, or encompassing the core promoter/TSS (Gazin et al. 2007). As specificity controls, we monitored binding of each cofactor to three irrelevant DNA regions and also analyzed enrichment using an irrelevant antibody (Supplemental Fig. S2). The chromatin immunoprecipitation (ChIP) results of Figure 1A show that of the 12 DNA-binding events analyzed, binding of ZFP354B, a zinc finger protein that contains a KRAB transcriptional repressor domain, was dependent on the fewest additional cofactors. Only

(C) 2013 Wajapeyee et al. This article is distributed exclusively by Cold Spring Harbor Laboratory Press for the first six months after the full-issue publication date (see http://genesdev.cshlp.org/site/misc/terms.xhtml). After six months, it is available under a Creative Commons License (AttributionNonCommercial 3.0 Unported), as described at http://creativecommons.org/ licenses/by-nc/3.0/. 


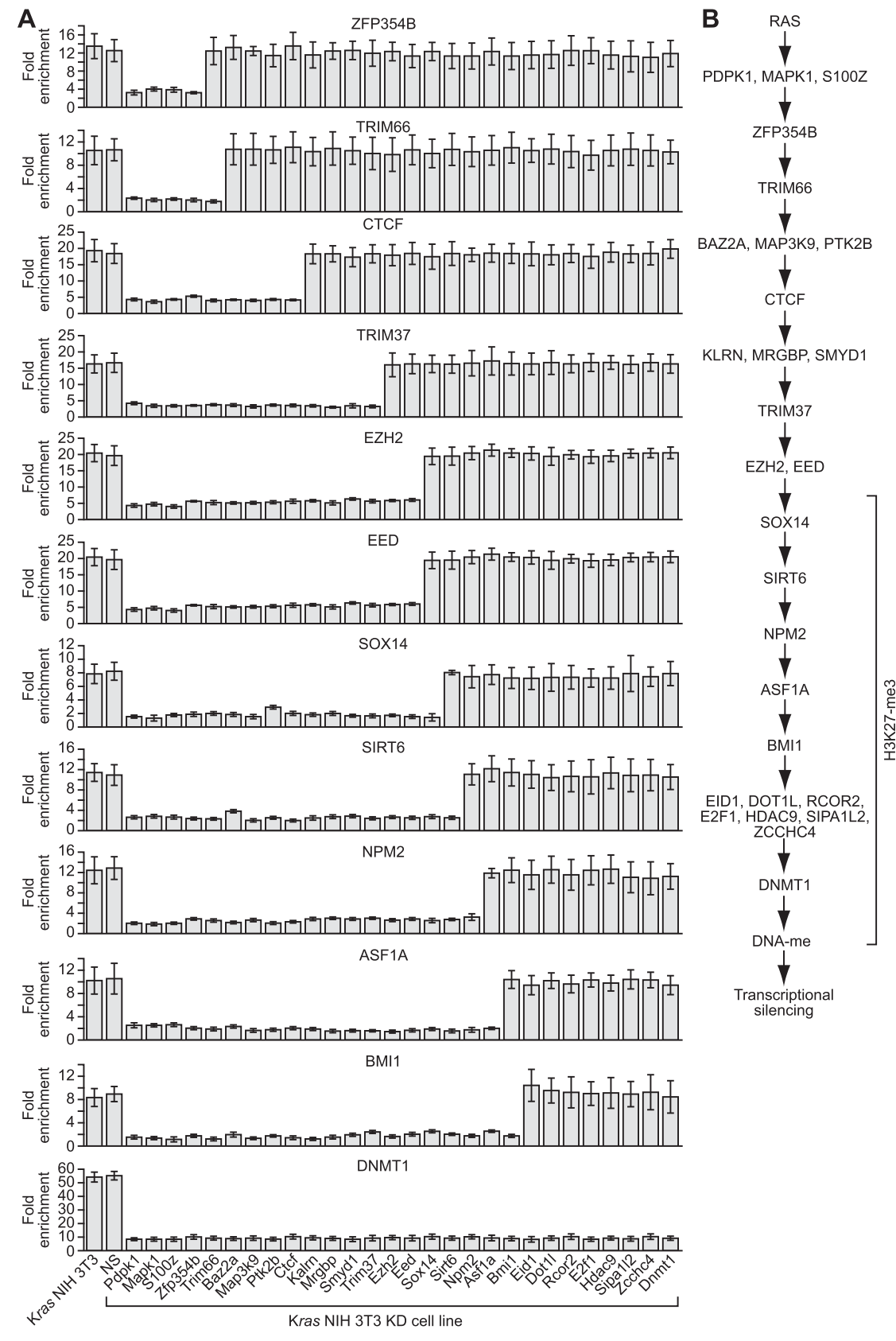

Figure 1. Delineation of a RAS-directed transcriptional silencing pathway. $(A)$ ChIP analysis monitoring binding of 12 cofactors to Fas in each of the Kras NIH 3T3 knockdown (KD) cell lines. The results are shown relative to that obtained in NIH 3T3 cells, which was set to 1. Error bars indicate SEM. $(B)$ Schematic of the RAS-directed silencing pathway. For steps at which the order of cofactors cannot be distinguished, the cofactors are aligned horizontally.

three cofactors (mitogen-activated protein kinase 1 [MAPK1], PDPK1, and S100Z), all of which have been implicated as cell signaling proteins /Gribenko et al. 2001; Downward 2003), were required for binding of ZFP354B to transcriptionally silenced Fas in Kras NIH $3 \mathrm{~T} 3$ cells. In contrast, binding of the DNA methyltransferase DNMT1 was dependent on all of the other 27 cofactors. The other 10 DNA-binding events analyzed showed a cofactor dependence that was intermediate to that of ZFP354B and DNMT1. The ChIP results of Figure
1A enabled us to construct a pathway that is summarized in Figure $1 \mathrm{~B}$ and discussed below.

Two of the cofactors, EZH2 and EED, are subunits of Polycomb repressive complex 2, which confers transcriptional repression through histone $\mathrm{H} 3$ Lys 27 trimethylation (H3K27me3) (Margueron and Reinberg 2011). We therefore measured H3K27me3 levels on Fas in the 28 Kras NIH 3 T3 knockdown cell lines. The results of Supplemental Figure S3 indicate that knockdown of EZH2 or EED and all factors upstream of EZH2 and EED resulted in loss of H3K27me3. In contrast, knockdown of components downstream from EZH2 and EED did not affect H3K27me3.

In our previous study, we showed that most of the 28 cofactors were also required for transcriptional silencing of several other TSGs in Kras NIH 3T3 cells (Gazin et al. 2007). To determine the generality of the pathway, we performed RNAi-based epistasis experiments for Sfrp1, one of the other TSGs analyzed in our previous study for which 25 of the 28 cofactors were required for silencing.

Supplemental Figure S4 shows the results of ChIP experiments analyzing binding of five representative cofactors (ZFP354B, CTCF, EZH2, BMI1, and DNMT1), which act at distinct steps of the pathway, in 25 Kras NIH 3T3 knockdown cell lines. Significantly, in all cases, the results on Sfrp1 were entirely consistent with those obtained with Fas.

The order of the RAS-directed transcriptional silencing pathway described above indicated that ZFP354B engages in the first sequence-specific DNAbinding interaction with Fas. We showed previously that expression of activated RAS in NIH 3T3 cells results in a large increase in ZFP354B protein levels (Gazin et al. 2007). These considerations raised the possibility that binding of ZFP354B may be the critical event that is sufficient to initiate and maintain Fas silencing.

To test this possibility, we asked whether increasing ZFP354B levels would result in transcriptional silencing of TSGs even in the absence of oncogenic RAS. Consistent with this idea, quantitative RT-PCR (qRT-PCR) analysis showed that ectopic expression of ZFP354B in NIH 3T3 cells (NIH 3T3/ZFP354B cells) (Supplemental Fig. S5A) resulted in substantial transcriptional repression of both Fas (Fig. 2A; see also Supplemental Fig. S5B) and Sfrp1 (Supplemental Fig. S6A).

We next performed a series of experiments to compare transcriptional repression resulting from ZFP354B overexpression with that resulting from oncogenic RAS. We showed previously that in Kras NIH 3T3 cells, the transcriptionally silenced TSGs are hypermethylated /Gazin 


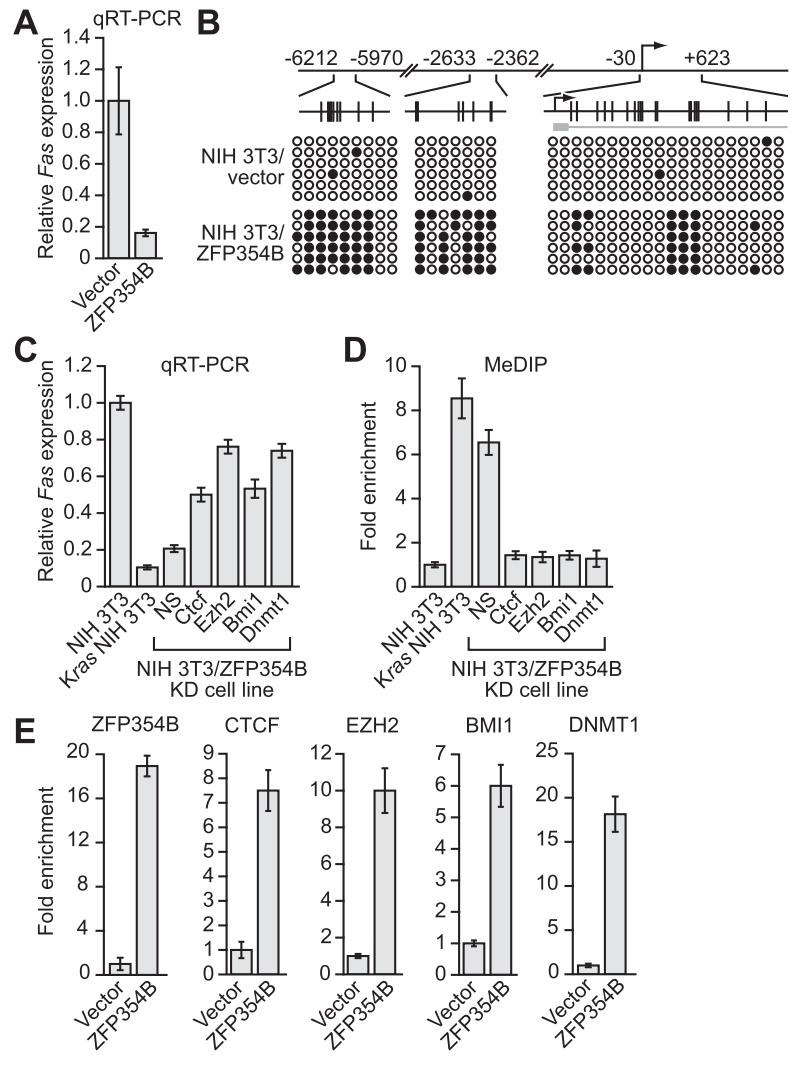

Figure 2. ZFP345B overexpression is sufficient to silence Fas in the absence of RAS. $(A, B)$ qRT-PCR analysis monitoring Fas expression $(A)$ and bisulfite sequence analysis of Fas $(B)$ in NIH 3 T3 cells stably expressing vector or ZFP354B. $(C, D)$ qRT-PCR analysis monitoring Fas expression $(C)$ and MeDIP analysis monitoring Fas DNA methylation $(D)$ in NIH 3T3/ZFP354B knockdown (KD) cell lines. As controls, Fas expression and DNA methylation were also monitored in NIH $3 \mathrm{~T} 3$ and Kras NIH 3T3 cells. (E) ChIP analysis monitoring binding of ZFP354B, CTCF, EZH2, BMI1, and DNMT1 to Fas in NIH $3 \mathrm{~T} 3$ cells stably expressing vector or ZFP354B. Error bars indicate SEM.

et al. 2007). We performed bisulfite sequencing in NIH 3T3/ ZFP354B cells, analyzing the same Fas and Sfrp1 regions previously found to be hypermethylated in Kras NIH 3T3 cells (Gazin et al. 2007). Bisulfite sequence analysis showed that in NIH 3T3/ZFP354B cells, both Fas (Fig. 2B) and Sfrp1 (Supplemental Fig. S6B) were hypermethylated.

We next asked whether transcriptional repression in NIH 3T3/ZFP354B cells was also dependent on cofactors that functioned downstream from ZFP354B. As in Kras NIH 3T3 cells (Gazin et al. 2007), knockdown of the representative downstream cofactor CTCF, EZH2, BMI1, or DNMT1 in NIH 3T3/ZFP354B cells reactivated Fas (Fig. 2C) and Sfrp1 (Supplemental Fig. S6C).

We also assessed DNA methylation following knockdown using a methylated DNA immunoprecipitation (MeDIP) assay. As expected, increased Fas or Sfrp1 transcription following knockdown of CTCF, EZH2, BMI, or DNMT1 in NIH 3T3/ZFP354B cells was accompanied by decreased DNA methylation (Fig. 2D; Supplemental Fig. S6D). Finally, ChIP analysis showed that in $\mathrm{NIH}$ 3T3/ZFP354B cells, as in Kras NIH 3T3 cells, ZFP354B itself as well as CTCF, EZH2, BMI1, and DNMT1 were bound to the transcriptionally silenced Fas (Fig.
2E) and Sfrp1 (Supplemental Fig. S6E) genes. Collectively, the results of Figure 2 and Supplemental Figure S6 demonstrate that overexpression of ZFP354B is sufficient to initiate transcriptional silencing of TSGs through a pathway similar to that directed by oncogenic RAS.

Oncogenic RAS stimulates several downstream signaling pathways, including the MAPK and phosphoinositide 3-kinase (PI3K)/AKT pathways (De Luca et al. 2012). To understand in greater detail the basis of RAS-mediated silencing of Fas, we first analyzed activating HRAS mutants that are defective for signaling through either the MAPK pathway [HRAS $(12 \mathrm{~V}, 40 \mathrm{C})]$ or the PI3K/AKT pathway [HRAS(12V,35S)] (White et al. 1995; RodriguezViciana et al. 1997; Hamad et al. 2002). The results of Figure $3 \mathrm{~A}$ show that neither mutant was able to promote Fas silencing, indicating the requirement for both the MAPK and PI3K/AKT pathways.

To confirm this conclusion, we analyzed chemical inhibitors of these signaling pathways. Kras NIH 3T3 cells were treated with a chemical inhibitor of either MAPK signaling (U0126, a selective inhibitor of MEK1 and MEK2) (Favata et al. 1998) or PI3K/AKT signaling (LY294002, a selective PI3K inhibitor) (Vlahos et al. 1994), and Fas expression was analyzed by qRT-PCR. The results of Figure 3B and Supplemental Figure S7A show that both inhibitors reactivated Fas expression, confirming that both the PI3K/AKT and MAPK pathways are required for RAS-directed transcriptional silencing of Fas. Consistent with this conclusion, among the 28 cofactors are PDPK1, a regulator of PI3K/AKT signaling (Raimondi and Falasca 2011), and MAPK1 and MAP3K9, regulators of MAPK signaling (Morrison 2012).

The availability of pharmacological inhibitors enabled us to study the reversibility and kinetics of RAS-directed transcriptional silencing. Figure 3C and Supplemental Figure S7B show that following addition of U0126 or LY294002 to Kras NIH 3T3 cells, Fas reactivation occurred within 24 or $36 \mathrm{~h}$, respectively. We next asked whether removal of the drugs would result in restoration of Fas silencing. Figure 3D and Supplemental Figure S7C show that following removal of U0126 or LY294002, Fas silencing was restored over a 48 -h time course. These results indicate that RAS-directed silencing of Fas occurs rapidly and is highly reversible.

To further study the reversibility and kinetics of RASdirected silencing of Fas, we analyzed representative cofactor binding as well as H3K27me3 and DNA methylation. The ChIP results of Figure $3 \mathrm{E}$ and Supplemental Figure S7D show that following addition of U0126 or LY294002, there was a progressive decrease in binding of ZFP354B, EZH2, and DNMT1 over 24-36 h, which correlated well with the kinetics of transcriptional reactivation (Fig. 3C; Supplemental Fig. S7B). Likewise, Figure $3 \mathrm{~F}$ and Supplemental Figure S7E show that removal of U0126 or LY294002 resulted in a progressive increase in binding of ZFP354B, EZH2, and DNMT1 over $\sim 48 \mathrm{~h}$, which correlated well with the kinetics of transcriptional silencing (Fig. 3D; Supplemental Fig. S7C). Notably, the loss of H3K27me3 and DNA methylation following addition of U0126 (Fig. 3G) or LY294002 (Supplemental Fig. S7F) and the acquisition of H3K27me3 and DNA methylation following removal of U0126 (Fig. 3H) or LY294002 (Supplemental Fig. S7G) were also well correlated with transcription and cofactor binding. 
Wajapeyee et al.
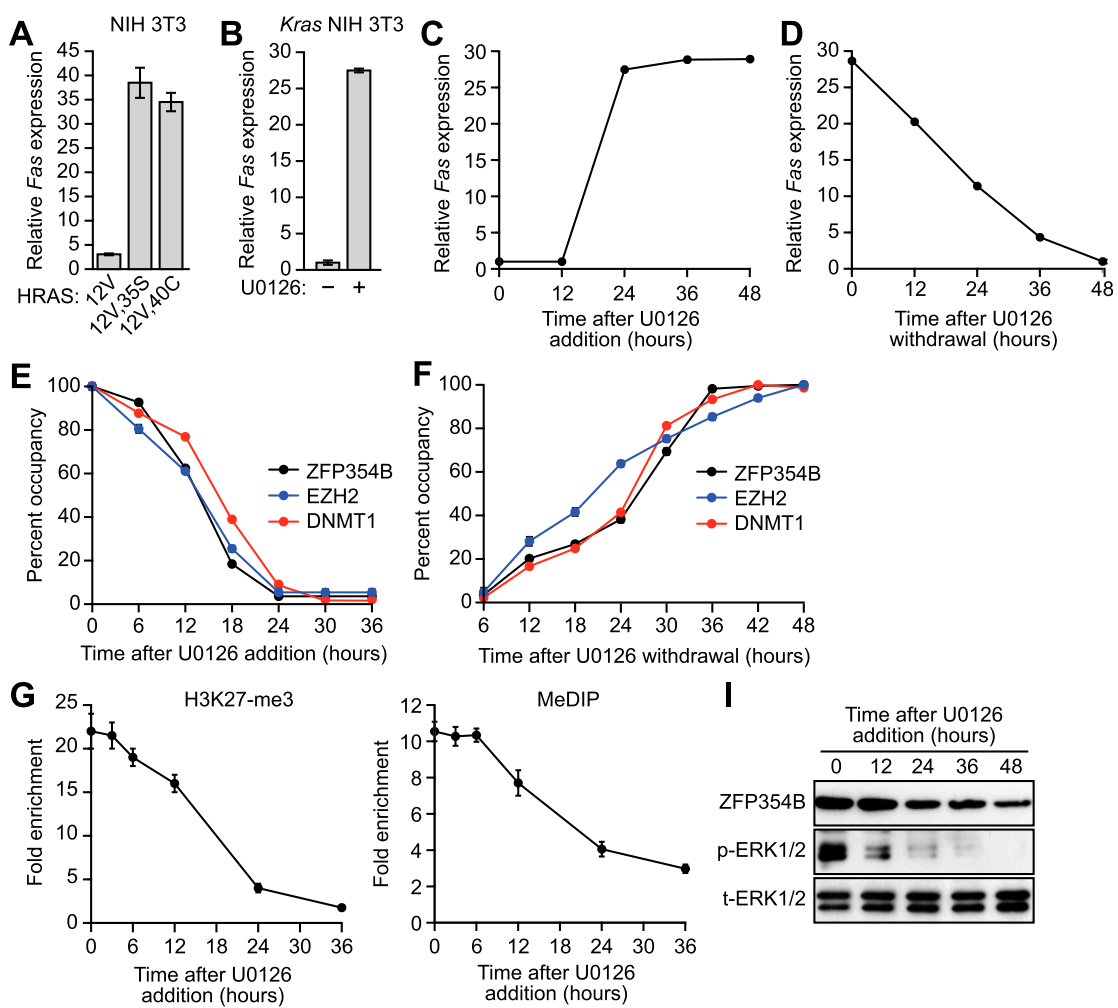

I
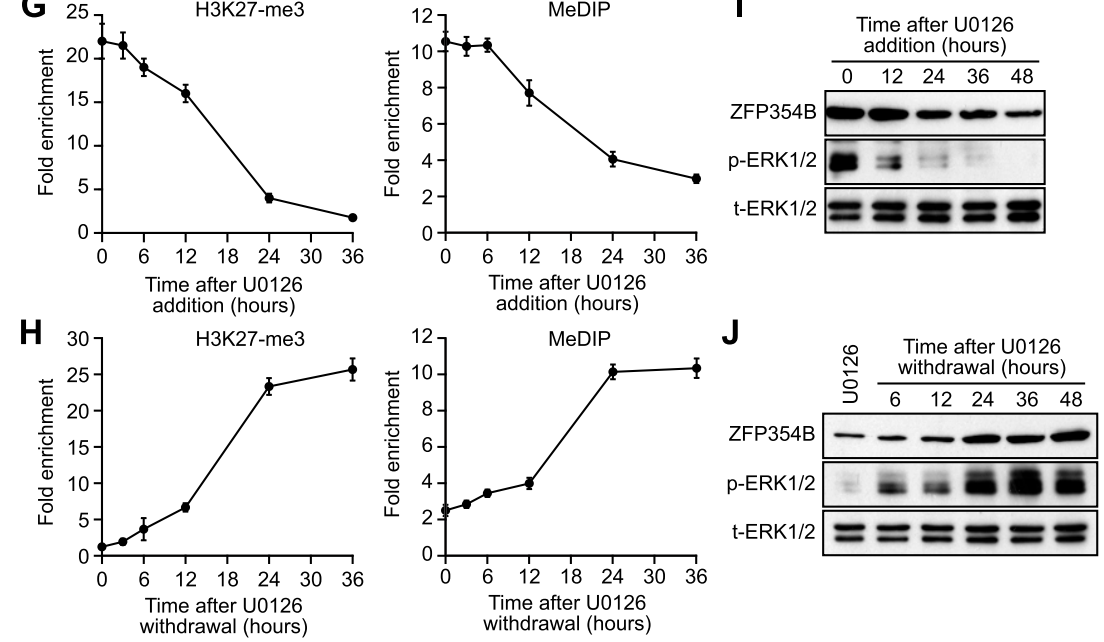

Figure 3. Kinetics of RAS-directed transcriptional silencing. (A) qRT-PCR analysis monitoring Fas expression in NIH 3T3 cells expressing HRAS mutants. The results were normalized to Fas expression in NIH $3 \mathrm{~T} 3$ cells, which was set to 1. (B) qRT-PCR analysis monitoring Fas expression in Kras NIH 3T3 cells treated in the absence and presence of U0126. $(C, D)$ qRT-PCR analysis monitoring Fas expression in Kras NIH 3T3 cells following U0126 addition $(C)$ or withdrawal $(D)$. Fas expression is shown relative to that observed in untreated KRas NIH 3T3 cells, which was set to $1 .(E, F)$ ChIP analysis monitoring binding of ZFP354B, EZH2, and DNMT1 to Fas in Kras NIH 3T3 cells following U0126 addition (E) or withdrawal $(F)$. Binding in Kras NIH 3 T3 cells is defined as $100 \%$ occupancy. $(G, H)$ ChIP analysis monitoring $\mathrm{H} 3 \mathrm{~K} 27 \mathrm{me} 3$ and DNA methylation on Fas in Kras NIH 3T3 cells following U0126 addition $(G)$ or withdrawal $(H)$. The results were normalized to that obtained in NIH 3T3 cells, which was set to 1. (I,J) Immunoblot analysis showing ZFP354B, phosphorylated ERK1/2 (p-ERK1/2), and total ERK1/2 (t-ERK1/2) levels in Kras NIH 3T3 cells following U0126 addition $(I)$ or withdrawal $(J)$. Error bars indicate SEM.

Finally, as expected, ZFP354B levels decreased following addition of U0126 (Fig. 3I) or LY294002 (Supplemental Fig. S7H) and increased following withdrawal of U0126 (Fig. 3J) or LY294002 (Supplemental Fig. S7H), with kinetics that correlated well with that of transcriptional activity.

Two mechanisms for DNA demethylation have been proposed (Wu and Zhang 2010). The first is the so-called passive mechanism, in which methyl groups are lost simply as a result of DNA replication. The second is an active mechanism in which a DNA demethylase catalyzes the removal of the methyl groups. The relatively rapid induction of Fas transcription and demethylation following pharmacological inhibition of RAS suggested that DNA demethylation was unlikely to result from a passive mechanism. Consistent with this possibility, when passive DNA methylation was blocked by addition of the DNA replication inhibitor aphidicolin, U0126 or LY294002 treatment still reactivated Fas expression (Supplemental Fig. S8A), which was accompanied by decreased methylation of Fas (Supplemental Fig. S8B).

In this study, we showed how RNAibased epistasis analysis can be used to order a defined set of components into a molecular pathway. The pathway is initiated by RAS, which then functions through a set of cell signaling proteins (MAPK1, PDPK1, and S100Z). The first DNA-binding event on Fas is by ZFP354B, followed by recruitment of additional DNA-binding proteins, multisubunit complexes, chromatinmodifying activities, and, finally, DNTM1 (Fig. 4). Collectively, these results indicate that RAS-directed silencing of Fas is a highly ordered process that ultimately establishes a platform for DNMT1 recruitment. This pathway of cofactor binding provides the underlying basis for a corresponding ordered establishment of repressive marks, including H3K27me3 and DNA methylation.

RAS initiates and maintains silencing by regulating levels of ZFP354B, which is the first cofactor to interact with Fas (Fig. 4). We note that all 28 cofactors may not act directly on Fas. Some cofactors, for example, may function by regulating expression or activity of other cofactors. Accordingly, we showed previously that PDPK1 regulates ZFP354B levels (Gazin et al. 2007).

Although we used RAS-transformed NIH 3T3 cells as an experimental system, for several reasons, we believe that our results have relevance to human cancers. For example, as in murine cells, activated RAS silences FAS in human cells (Urquhart et al. 2002; Gazin et al. 2007). Moreover, FAS silencing also occurs in some transformed cells, human tumors, and mouse models of cancer and has been shown to be relevant to both tumor progression (for example, see Hopkins-Donaldson et al. 2003) and chemotherapeutic resistance (Maecker et al. 2002). In addition, we showed previously that this same pathway also mediates silencing of other TSGs, including Lox, Par4/Pawr, and Plag11, which have been found to be relevant to cellular transformation and cancer (for discussion, see Gazin et al. 2007). Finally, several of the components of the pathway that we describe have been shown to cooperate with RAS in transformation of human cells (Croonquist and Van Ness 2005; Datta et al. 2007) or are 


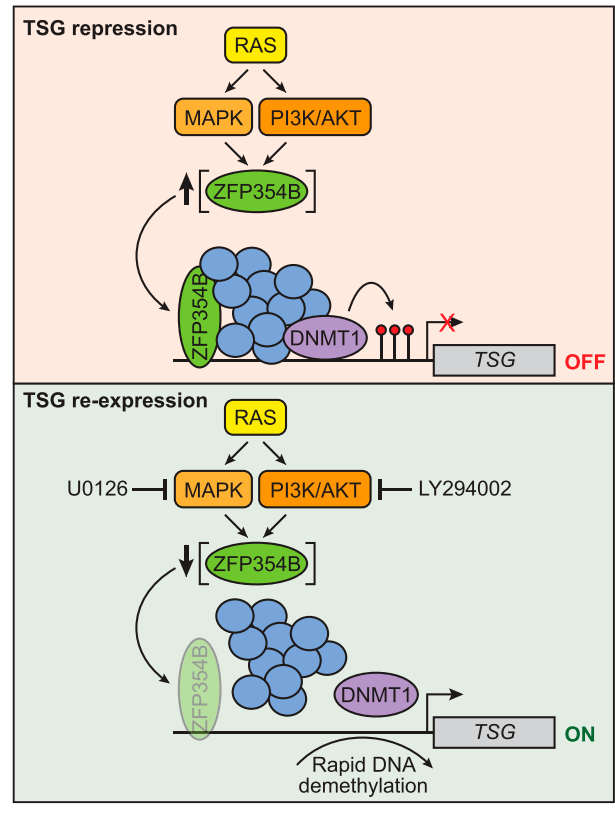

Figure 4. Model for RAS-directed silencing of TSGs. (Top) RAS signaling through the MAPK and PI3K/AKT pathways results in increased levels of ZFP354B, which binds to the TSG promoter and initiates recruitment of other cofactors (which may or may not bind directly to ZFP354B). Recruitment of DNMT1 leads to methylation of the promoter and silencing of TSG expression. (Bottom) The RAS-directed signaling pathway can be targeted through pharmacological inhibition of MAPK or PI3K/AKT, which leads to reduced levels of ZFP354B. In the absence of ZFP354B binding, association of other cofactors with the promoter cannot be maintained, and, in conjunction with rapid DNA demethylation, the TSG is re-expressed.

overexpressed in human cancers and contribute to the transformed phenotype (Chang and Hung 2012; Jin and Robertson 2013).

Our results indicate that RAS-directed transcriptional silencing of TSGs is not truly epigenetic because RAS is required for not only initiation of the pathway but also maintenance of repression. The continual requirement for RAS and the components of the RAS-directed silencing pathway and the rapid reversibility of TSG silencing may have therapeutic implications. The components through which RAS and other oncoproteins direct TSG silencing in human cancers can be identified using functional genomic approaches such as those we described and represent potential anti-cancer targets.

\section{Materials and methods}

\section{Cell lines and culture}

NIH 3T3 (American Type Culture Collection [ATCC] no. CRL-1658) and Kras NIH 3T3 (ATCC no. CRL-6361) cells were maintained in DMEM supplemented with $10 \%$ FCS at $37^{\circ} \mathrm{C}$ and $5 \% \mathrm{CO}_{2}$. To derive NIH 3T3/ ZFP354B cells, full-length Zfp354b was PCR-amplified from a cDNA (Open Biosystems, no. BC107400) and cloned into the vector 3xFlag-MycCMV-26 (Sigma). The construct was linearized and transfected into NIH $3 \mathrm{~T} 3$ cells, which were selected with $500 \mu \mathrm{g} / \mathrm{mL}$ neomycin for $3 \mathrm{wk}$. To construct cell lines stably expressing RAS mutants, HEK293T cells were transfected with $2 \mu \mathrm{g}$ of pBABE-HRAS(12V), pBABE-HRAS(12V,35S), or
pBABE-HRAS(12V,40C) (Addgene). Viral supernatants were collected $48 \mathrm{~h}$ later and used to infect NIH $3 \mathrm{~T} 3$ cells followed by selection with $2 \mu \mathrm{g} / \mathrm{mL}$ puromycin. For drug addition experiments, Kras NIH 3T3 cells were treated with dimethyl sulfoxide (DMSO), $10 \mu \mathrm{M}$ U0126 (Cell Signaling Technology, Inc.), or $20 \mu \mathrm{M}$ LY294002 (Calbiochem) for $48 \mathrm{~h}$ unless otherwise stated. For drug withdrawal experiments, cells were treated with U0126 or LY294002 for 36 or $48 \mathrm{~h}$ and then grown in fresh medium without inhibitors.

\section{RNAi}

Individual knockdown cell lines were generated by retroviral transduction of $0.6 \times 10^{5}$ Kras NIH 3T3 or NIH 3T3/ZFP354B cells with the target shRNA (Supplemental Table S1).

\section{ChIP analysis}

ChIP assays were performed as previously described (Gazin et al. 2007) using ASF1A (Millipore), BMI1 (Abcam), CTCF (Upstate Biotechnology), DNMT1 (Imgenex), EED (Millipore), EZH2 (Cell Signaling Technology), NPM2 (a gift from M.M. Matzuk), SIRT6 (Aviva Systems Biology), SOX14 (Santa Cruz Biotechnology), TRIM37 (a gift from A.E. Lehesjoki), TRIM66 (a gift from R. Losson), ZFP354B (Gazin et al. 2007), or H3K27me3 (Millipore) antibodies. Primer sequences used for amplifying ChIP products are provided in Supplemental Table S2.

Normalized Ct $(\Delta \mathrm{Ct})$ values were calculated by subtracting the $\mathrm{Ct}$ obtained with input DNA from that obtained with immunoprecipitated DNA $[\Delta \mathrm{Ct}=\mathrm{Ct}(\mathrm{IP})-\mathrm{Ct}($ input $)]$. Relative fold enrichment of a factor at the target site was then calculated using the formula $\left.2^{-[\Delta \mathrm{Ct} \mid \mathrm{T})}-\Delta \mathrm{Ct}(\mathrm{Actb})\right]$, where $\Delta \mathrm{Ct}(\mathrm{T})$ and $\Delta \mathrm{Ct}(\mathrm{Actb})$ are $\Delta \mathrm{Ct}$ values obtained using target and Actb (irrelevant) primers, respectively.

\section{$q R T-P C R$}

Total RNA was isolated and reverse-transcribed, and qRT-PCR was performed as described previously (Gazin et al. 2007) using primers listed in Supplemental Table S3.

\section{MeDIP analysis}

MeDIP assays were performed as described (Gazin et al. 2007). Relative quantification of DNA fragments for each region was determined by plotting $\mathrm{Ct}$ values on the standard curve. Fold difference of immunoprecipitated over input DNA was calculated to indicate enrichment levels of the target region. All assays were conducted on at least two biological replicates.

\section{Bisulfite sequencing analysis}

Bisulfite modification and sequencing were carried out as previously described (Gazin et al. 2007) using primer sequences listed in Supplemental Table S2.

\section{Immunoblot analysis}

Cell extracts were prepared as previously described (Santra et al. 2009). Blots were probed with ZFP354B (Gazin et al. 2007), phospho-AKT, total AKT, phospho-ERK1/2, total ERK1/2 (Cell Signaling), or $\alpha$-tubulin antibodies.

\section{Acknowledgments}

We thank C. Gazin for initial contributions to this study; A. Lehesjoki, R. Losson, and M. Matzuk for providing reagents; the University of Massachusetts Medical School RNAi Core Facility for providing shRNAs; and S. Deibler for editorial assistance. N.W. is a Sidney Kimmel Scholar for Cancer Research and is supported by young investigator awards from the National Lung Cancer Partnership/Uniting Against Lung Cancer, Melanoma Research Alliance, and International Association for the Study of Lung Cancer. This work was supported by a grant from the NIH 
Wajapeyee et al.

(R01GM033977) to M.R.G., who is also an investigator of the Howard Hughes Medical Institute.

\section{References}

Berger AH, Knudson AG, Pandolfi PP. 2011. A continuum model for tumour suppression. Nature 476: 163-169.

Chang CJ, Hung MC. 2012. The role of EZH2 in tumour progression. Br J Cancer 106: 243-247.

Croonquist PA, Van Ness B. 2005. The polycomb group protein enhancer of zeste homolog 2 (EZH 2) is an oncogene that influences myeloma cell growth and the mutant ras phenotype. Oncogene 24: 62696280 .

Datta S, Hoenerhoff MJ, Bommi P, Sainger R, Guo WJ, Dimri M, Band H, Band V, Green JE, Dimri GP. 2007. Bmi-1 cooperates with H-Ras to transform human mammary epithelial cells via dysregulation of multiple growth-regulatory pathways. Cancer Res 67: 1028610295.

De Luca A, Maiello MR, D'Alessio A, Pergameno M, Normanno N. 2012. The RAS/RAF/MEK/ERK and the PI3K/AKT signalling pathways: Role in cancer pathogenesis and implications for therapeutic approaches. Expert Opin Ther Targets 16: S17-S27.

Downward J. 2003. Targeting RAS signalling pathways in cancer therapy. Nat Rev Cancer 3: 11-22.

Favata MF, Horiuchi KY, Manos EJ, Daulerio AJ, Stradley DA, Feeser WS, Van Dyk DE, Pitts WJ, Earl RA, Hobbs F, et al. 1998. Identification of a novel inhibitor of mitogen-activated protein kinase kinase. $I$ Biol Chem 273: 18623-18632.

Gazin C, Wajapeyee N, Gobeil S, Virbasius CM, Green MR. 2007. An elaborate pathway required for Ras-mediated epigenetic silencing. Nature 449: 1073-1077.

Gribenko AV, Hopper JE, Makhatadze GI. 2001. Molecular characterization and tissue distribution of a novel member of the S100 family of EF-hand proteins. Biochemistry 40: 15538-15548.

Hamad NM, Elconin JH, Karnoub AE, Bai W, Rich JN, Abraham RT, Der CJ, Counter CM. 2002. Distinct requirements for Ras oncogenesis in human versus mouse cells. Genes Dev 16: 2045-2057.

Hanahan D, Weinberg RA. 2011. Hallmarks of cancer: The next generation. Cell 144: 646-674.

Hopkins-Donaldson S, Ziegler A, Kurtz S, Bigosch C, Kandioler D, Ludwig C, Zangemeister-Wittke U, Stahel R. 2003. Silencing of death receptor and caspase-8 expression in small cell lung carcinoma cell lines and tumors by DNA methylation. Cell Death Differ 10: 356364.

Jin B, Robertson KD. 2013. DNA methyltransferases, DNA damage repair, and cancer. Adv Exp Med Biol 754: 3-29.

Kulis M, Esteller M. 2010. DNA methylation and cancer. Adv Genet 70: 27-56.

Maecker HL, Yun Z, Maecker HT, Giaccia AJ. 2002. Epigenetic changes in tumor Fas levels determine immune escape and response to therapy. Cancer Cell 2: 139-148.

Margueron R, Reinberg D. 2011. The Polycomb complex PRC2 and its mark in life. Nature 469: 343-349.

Morrison DK. 2012. MAP kinase pathways. Cold Spring Harb Perspect Biol 4: a011254.

Peli J, Schroter M, Rudaz C, Hahne M, Meyer C, Reichmann E, Tschopp J. 1999. Oncogenic Ras inhibits Fas ligand-mediated apoptosis by downregulating the expression of Fas. EMBO J 18: 1824-1831.

Ptashne M. 2007. On the use of the word 'epigenetic'. Curr Biol 17: R233R236.

Raimondi C, Falasca M. 2011. Targeting PDK1 in cancer. Curr Med Chem 18: $2763-2769$.

Rodriguez-Viciana P, Warne PH, Khwaja A, Marte BM, Pappin D, Das P, Waterfield MD, Ridley A, Downward J. 1997. Role of phosphoinositide $3-\mathrm{OH}$ kinase in cell transformation and control of the actin cytoskeleton by Ras. Cell 89: 457-467.

Santra MK, Wajapeyee N, Green MR. 2009. F-box protein FBXO31 mediates cyclin D1 degradation to induce G1 arrest after DNA damage. Nature 459: 722-725.

Urquhart JL, Meech SJ, Marr DG, Shellman YG, Duke RC, Norris DA. 2002. Regulation of Fas-mediated apoptosis by N-ras in melanoma. I Invest Dermatol 119: 556-561.
Vlahos CJ, Matter WF, Hui KY, Brown RF. 1994. A specific inhibitor of phosphatidylinositol 3-kinase, 2-(4-morpholinyl)-8-phenyl-4H-1benzopyran-4-one (LY294002). J Biol Chem 269: 5241-5248.

Vogelstein B, Papadopoulos N, Velculescu VE, Zhou S, Diaz LA Jr, Kinzler KW. 2013. Cancer genome landscapes. Science 339: 1546-1558.

White MA, Nicolette C, Minden A, Polverino A, Van Aelst L, Karin M, Wigler MH. 1995. Multiple Ras functions can contribute to mammalian cell transformation. Cell 80: 533-541.

Wu SC, Zhang Y. 2010. Active DNA demethylation: Many roads lead to Rome. Nat Rev Mol Cell Biol 11: 607-620. 


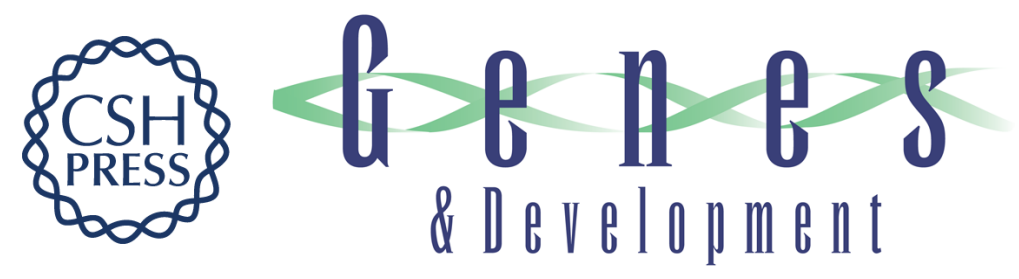

\section{Oncogenic RAS directs silencing of tumor suppressor genes through ordered recruitment of transcriptional repressors}

Narendra Wajapeyee, Sunil K. Malonia, Rajendra K. Palakurthy, et al.

Genes Dev. 2013, 27: originally published online October 8, 2013

Access the most recent version at doi:10.1101/gad.227413.113

\section{Supplemental http://genesdev.cshlp.org/content/suppl/2013/10/03/gad.227413.113.DC1 Material}

References This article cites 27 articles, 6 of which can be accessed free at: http://genesdev.cshlp.org/content/27/20/2221.full.html\#ref-list-1

Creative This article is distributed exclusively by Cold Spring Harbor Laboratory Press for the first Commons six months after the full-issue publication date (see

License http://genesdev.cshlp.org/site/misc/terms.xhtml). After six months, it is available under a Creative Commons License (Attribution-NonCommercial 3.0 Unported), as described at http://creativecommons.org/licenses/by-nc/3.0/.

Email Alerting Receive free email alerts when new articles cite this article - sign up in the box at the top Service right corner of the article or click here.

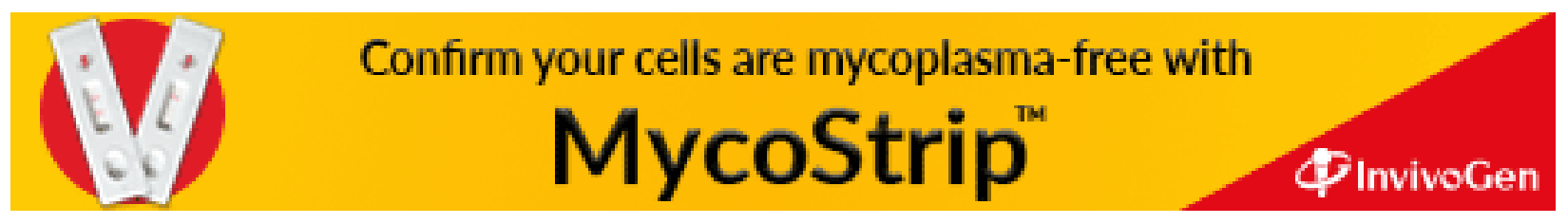

